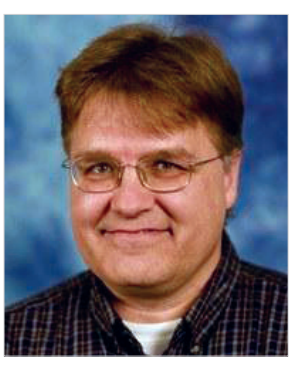

\title{
Some Last Thoughts on Leadership, Tradition and Change
}

Because of our traditions, we've kept our balance for many, many years. Here in Anatevka, we have traditions for everything... How to sleep, how to eat. . how to work. . how to wear clothes. For instance, we always keep our heads covered and always wear a little prayer shawl. This shows our constant devotion to God. You may ask, "How did this tradition get started?" I'll tell you.

I don't know. But it's a tradition . . and because of our traditions. ... Every one of us knows who he is and what God expects him to do.

- Tevye, Fiddler on the Roof

$\mathbf{M}$ y daughter's high school recently did a wonderful production of the classic musical, Fiddler on the Roof. It's a timeless message of a father's love and devotion for his daughters in the midst of incredible cultural and political change. I've seen this musical many times in my life, but I was struck afresh with the incredible tension Tevye felt as a father between "what was expected" and the future happiness of his daughters.

GODORT has been around long enough to create many traditions. If Tevye is right, traditions serve an important role in helping leaders know what is expected of us. The problem is that once our traditions no longer reflect who we are, it becomes difficult for leaders to know what is expected of them. This in a nut shell is the predicament that GODORT finds itself facing. We simply have a choice whether or not we are willing to create new traditions that align with our current expectations and the future happiness of our members or not.

For my final column I would like to focus on this topic of expectations, looking at some of the ways those shape how we can look at leadership in our community.

\section{Leadership and Expectations}

What expectations should we have of leaders in a volunteer organization? Most would agree that the expectations are different from those that come with a salaried position, but in what ways? If we wanted to I suppose we could compare things such as skills, time and other factors to determine how one quantitatively differs from the other. However, this approach would never fully satisfy the multitude of opinions that would emerge from an exercise like this. We would all simply have different expectation about what quantities are realistic.

The more helpful question to address is: What expectations leaders have of themselves? I would submit that a leaders expectations are shaped and defined by the incentives that convince them to take on these roles. These incentives may come from external force such as job responsibilities, promotional expectations, or even collegial pressure. However, often there are internal incentives associated with the leader's personality that play a critical role. These are often described in negative or positive reflections by their followers with words like caring, ambitious, or even driven.

Gallup's Strength Finder survey (www.strengthstest.com/ strengthsfinderthemes/strengths-themes.html) of leadership characteristics identifies 34 different types of internal incentives. The purpose of this taxonomy is to encourage people to lead out of their strengths and to also help people understand the power behind understanding their own motivations. It is internal incentives that get to the heart of good leadership. When the external reasons for leading either no longer exist or are outweighed by egregious circumstances then "who you are" is all that is left.

Does this imply that a leader's internal incentive will always circumvent tough circumstances? Certainly not. Over the years, GODORT memberships' expectations of its leaders and the leaders own expectations of the positions in which they agreed to serve, have not always aligned. There are multifarious reasons for why this is true, from declining membership, to expanding responsibilities of its members, as well as local institutional budgetary constraints, just to name a few. The bottom line is that in some cases the internal incentives no longer outweigh some of our leadership opportunities. So how do we move forward?

\section{Leadership with a Focus}

Are we simply asking too much of our leaders? Most would agree that our members no longer have jobs that will allow them to simply focus only on issues related to government information. What this means is that our leaders are being pulled in many different directions at work, requiring them to be involved in many other professional domains. Consequently, our leaders have less time to devote their efforts solely to one organization.

One way to handle this dilemma is to provide leadership opportunities that have a very specific set of focused responsibilities that a prospective leaders would be willing to take on. 
For example, rather than expecting our taskforce coordinators to be involved in all the activities of the working committees, they could serve a very specific function focusing on information dissemination through programming, webinars, and discussion groups.

\section{Leadership in the Virtual World}

We are aware that the traditional expectation that our leaders physically attend ALA conferences is becoming more unreasonable to due to budgetary constraints. Even though we recognize that some activities require some physical presence at ALA meetings, there are many technological solutions that provide our leaders with alternate opportunities for providing leadership.

However, some are making assumptions about technology that makes it more difficult to recruit excellent leaders. First, we cannot assume that all of our leaders have the technical savvy to run virtual meetings or to provide virtual leadership. Second, it is one thing to understand how to use technology and quite another thing to know how to provide leadership virtually.

We need to seriously reconsider what types of mechanisms and training we can provide for our leaders so they can effectively use the new solutions technology offers. We want them to be able to conduct virtual meetings and project with the same confidence that they would have if they were conducting a face-to-face meeting. We don't want technology to be a barrier that would keep potential leaders from volunteering.

\section{Creating New Traditions}

GODORT has a cohort of new government information specialists emerging in our midst who have a wonderful mix of internal incentives to lead. At the same time, there is also a strong leadership cohort of members that no longer identify with a traditional government documents department. It is imperative that we position ourselves to not simply change, but to create new traditions for GODORT that reflect who we are and the changing world in which we work

As Tevye did, we need to and ask "How did these traditions get started?" Do they reflect who we are? And are they useful. If not, we need to make some new traditions. 